\title{
Non-Thermal Plasma Technology for the Abatement of NOx and SOx from the Exhaust of Marine Diesel Engine
}

\author{
N. Manivannan, W. Balachandran, R. Beleca, and M. Abbod
}

\begin{abstract}
Non-thermal plasma based technology is proposed to the abatement of NOx and SOx of the exhaust gas from marine diesel engine. Proposed technology uses electron gun and microwave energy to generate the plasma. Fundamentals of non-thermal plasma and chemistry are presented with a set of simulation results of the reduction of NOx and $\mathrm{SO}_{2}$ for a typical two stoke marine diesel exhaust engine which is supported by an experimental results obtained with microwave plasma. A new scheme is also proposed in this paper to generate required plasma for the treatment of NOx and SOx form high exhaust flow rate.
\end{abstract}

Index Terms-Abatement of NOx and SOx, non-thermal plasma, marine diesel emission control, electron beam plasma and Microwave plasma.

\section{INTRODUCTION}

Non-thermal plasma technology for the abatement of $\mathrm{NOx}\left(\mathrm{NO}+\mathrm{NO}_{2}\right)$ and $\mathrm{SOx}$ from marine diesel engine exhaust gas is addressed in this paper. The toxic gases (NOx and SOx) are harmful to human health (cancer, respiratory irritation, nervous system problems, and birth defects) and environment (acid rain, ozone production, eutrophication, acidification of lakes and streams, accelerated corrosion of buildings and monuments, and reduced visibility) [1], [2]. IMO's MARPOL Annex VI, regulation 13 and regulation 14 defines the emission limits of NOx and SOx from marine exhaust [3], [4].

There are number of technologies those have been implemented on board to reduce the level of NOx and SOx from marine diesel engine [5]. Though these technologies can remove $99 \%$ of $\mathrm{SOx}$ and $90 \%$ of NOx, they possess number of drawbacks; two separate technologies for removal of NOx and SOx, requires high installation cost as well as maintenance cost, the installation takes large space on the ship and requires large storage of ammonia is required for the removal of NOx [5], [6]. On other hand, it has been proved and utilized that Non-Thermal Plasma (NTP) technology has number advantages in depollution in power plant such as simultaneous removal of NOx and SOx and reduced energy requirements [7].

There are a number of ways non-thermal plasma can be generated; Dielectric Barrier Discharge (DBD), Corona Discharge (CD), Electron Beam Generated Plasma (EBGP)

Manuscript received April 22, 2013; revised July 16, 2013. This work has been supported by the DEECON project, grant number 284745 funded by the EC Seventh Framework Programme theme FP7-SST-2011-RTD-1.

The authors are with CESR of School of Engineering and Design, Brunel University, Uxbridge, UB8 3PH, UK (e-mail: Nadarajah.Manivannan@brunel.ac.uk). and Microwave Plasma (MP). Out of these ENGP has been implemented for high throughput applications such as power plants to control the pollutions [8]. Electron beam can generate high density of electrons with high energy as required to generate high energy plasma. However non-of these NTP technologies have been studied or used in the marine industry in any form to remove NOx and SOx.

In this paper, we propose Electron Beam (EB) + Microwave Wave (MW) based NTP scheme to reduce NOx and SOx from the marine diesel engine. The major idea behind the combination of $\mathrm{EB}$ and $\mathrm{MW}$ is that, while $\mathrm{EB}$ can produce enough electrons to generate plasma, MW would maintain the energy of those electrons by reenergizing them. This combination would reduce the energy requirements that of using $\mathrm{EB}$ alone to generate same energy of plasma. Furthermore, since $\mathrm{EB}+\mathrm{MW}$ plasma is electrode-less system, it avoids the problem of contamination.

The paper is structured in the following ways; Section I presents the basics of physics and chemistry NTP, in particular, for the typical gas composition of marine exhaust and Section II presents a set-of simulation result of reduction efficiency of NOx and SOx for a typical twostroke marine diesel engine along with experimental results obtained with MP. The proposed new scheme, combination of $\mathrm{MW}$ and $\mathrm{EB}$, is presented in the section III and finally conclusions are drawn in the Section IV.

\section{NON-Thermal Plasma ChEMISTRY AND PHysics}

The basic principle of non-thermal plasma is that electron temperature $(\mathrm{Te})$ and gas temperature $(\mathrm{Tg})$ is greatly differ such that $T_{e} \gg T_{g}$. High energy electrons impact with gas molecules and produce various radicals and ions. In the case of exhaust gas of marine diesel engine which composes of high concentration of $\mathrm{CO}_{2}, \mathrm{H}_{2} \mathrm{O}, \mathrm{N}_{2}$ and low concentrations of $\mathrm{NOx}$, and $\mathrm{SO}_{2}$, particulate matters (PM), hydro carbon(HC), volatile organic compounds (VOC) and soot particles, the major radicals produced will be $\mathrm{OH} \cdot \mathrm{O}$, $\mathrm{N} \cdot$ and $\mathrm{H} \cdot$. When these radicals interact with $\mathrm{NOx}$ and SOx, they will be turned into $\mathrm{H}_{2} \mathrm{SO}_{4}$ and $\mathrm{HNO}_{3}$ respectively. These acids can be dissolved into sea water after adjusting the $\mathrm{pH}$ levels.

Radical formations and radical + molecule reactions are very fast and highly depend on the reaction rates. While reaction rate of electron impact depends on the electron energy and cross-section of impact, reaction rate of radical + molecules depend on the chemistry and temperature of the gas. The reactions given Table I play dominant role in the formation of radicals and conversion of NOx and SOx into $\mathrm{H}_{2} \mathrm{SO}_{4}$ and $\mathrm{HNO}_{3}$; 
TABLE I: Plasma ChEMistry AND AsSOCIATED REACTIONS RATE CONSTANTS OF THE CONVERSION OF NOX AND $\mathrm{SO}_{2} \mathrm{INTO} \mathrm{H}_{2} \mathrm{SO}_{4} \mathrm{AND} \mathrm{HNO}_{3}$. TREPRESENTS TEMPERATURE OF GAS.

\begin{tabular}{|c|c|c|c|}
\hline \multirow[b]{2}{*}{ Reactions } & \multicolumn{2}{|r|}{ Reaction Rate [9], [10] } & \multirow[b]{2}{*}{ Index } \\
\hline & Symbols & $\begin{array}{c}\text { Value } \\
\left(\mathrm{cm}^{3} \text { molecule }^{-1} \mathrm{~s}^{-1}\right)\end{array}$ & \\
\hline $\mathrm{e}+\mathrm{H}_{2} \mathrm{O} \rightarrow \mathrm{OH}^{-}+\mathrm{H}^{-}+\mathrm{e}$ & $\mathrm{k}_{\mathrm{d} 1}$ & \multirow{4}{*}{ See Fig. 1} & (R1) \\
\hline $\mathrm{e}+\mathrm{O}_{2} \rightarrow \mathrm{O}^{\circ}+\mathrm{O}^{\prime}+\mathrm{e}$ & $\mathrm{k}_{\mathrm{d} 2}$ & & (R2) \\
\hline $\mathrm{e}+\mathrm{O}_{2} \rightarrow \mathrm{O}+\mathrm{O}^{*}+\mathrm{e}$ & $\mathrm{k}_{\mathrm{d} 3}$ & & (R3) \\
\hline $\mathrm{e}+\mathrm{N}_{2} \rightarrow \mathrm{N}^{\prime}+\mathrm{N}^{\prime}+\mathrm{e}$ & $\mathrm{k}_{\mathrm{d} 4}$ & & (R4) \\
\hline $\mathrm{O}^{*}+\mathrm{H}_{2} \mathrm{O} \rightarrow \mathrm{OH}^{-}+\mathrm{OH}^{-}$ & $\mathrm{k}_{\mathrm{e} 1}$ & $2.2 \times 10^{-10}$ & (R5) \\
\hline $\mathrm{NO}+\mathrm{O}^{-}+\mathrm{M} \rightarrow \mathrm{NO}_{2}+\mathrm{M}$ & $\mathrm{k}_{1}$ & $3.0 \times 10^{-11}(\mathrm{~T} / 300)^{0.3}$ & (R6) \\
\hline $\mathrm{NO}+\mathrm{OH}^{-}+\mathrm{M} \rightarrow \mathrm{HNO}_{2}+\mathrm{M}$ & $\mathrm{k}_{2}$ & $2.5 \times 10^{-12} \exp (260 / \mathrm{T})$ & (R7) \\
\hline $\mathrm{HNO}_{2}+\mathrm{OH} \rightarrow \mathrm{NO}_{2}+\mathrm{H}_{2} \mathrm{O}$ & $\mathrm{k}_{3}$ & $3.3 \times 10^{-11}(\mathrm{~T} / 300)^{-0.3}$ & (R8) \\
\hline $\mathrm{NO}_{2}+\mathrm{OH}+\mathrm{M} \rightarrow \mathrm{HNO}_{3}+\mathrm{M}$ & $\mathrm{k}_{4}$ & $4.1 \times 10^{-11}$ & (R9) \\
\hline $\mathrm{SO}_{2}+\mathrm{OH}^{-}+\mathrm{M} \rightarrow \mathrm{HSO}_{3}+\mathrm{M}$ & $\mathrm{k}_{5}$ & $1.3 \times 10^{-12}(\mathrm{~T} / 300)^{-0.7}$ & (R10) \\
\hline $\mathrm{HSO}_{3}+\mathrm{O}_{2} \rightarrow \mathrm{SO}_{3}+\mathrm{HO}_{2}$ & $\mathrm{k}_{6}$ & $1.1 \times 10^{-13} \exp (-1200 / \mathrm{T})$ & (R11) \\
\hline $\mathrm{SO}_{3}+\mathrm{H}_{2} \mathrm{O} \rightarrow \mathrm{H}_{2} \mathrm{SO}_{4}$ & $\mathrm{k}_{7}$ & $3.9 \times 10^{-41} \exp (6830 / \mathrm{T})\left[\mathrm{H}_{2} \mathrm{O}\right]^{2}$ & (R12) \\
\hline $\mathrm{N}^{-}+\mathrm{OH}^{-} \rightarrow \mathrm{NO}^{\circ}+\mathrm{H}^{-}$ & $\mathrm{k}_{8}$ & $3.8 \times 10^{-11} \exp (85 / \mathrm{T})$ & (R13) \\
\hline $\mathrm{N}^{\prime}+\mathrm{NO} \rightarrow \mathrm{N}_{2}+\mathrm{O}^{\prime}$ & $\mathrm{k}_{9}$ & $3.1 \times 10^{-11}$ & (R14) \\
\hline $\mathrm{N}^{-}+\mathrm{NO}_{2} \rightarrow \mathrm{N}_{2} \mathrm{O}+\mathrm{O}^{\prime}$ & $\mathrm{k}_{10}$ & $3.0 \times 10^{-12}$ & (R15) \\
\hline
\end{tabular}

Table I also gives associated reaction rate constants of the radical + gas reactions and reactions rate constants of the electron impact reactions $\left(k_{d 1}, k_{d 2}, k_{d 3}\right.$ and $\left.k_{d 4}\right)$ are calculated using the following equations (1) and (2);

$$
k d_{j}=\sqrt{\frac{2 q}{m_{e}}} \int_{0}^{\infty} \varepsilon \sigma_{j}(\varepsilon) f(\varepsilon) d \varepsilon
$$

where, $q$ - charge of the electron, $e ; m_{e}$ - mass of the electron; $\varepsilon$ - electron energy $(\mathrm{V}), \sigma_{j}$ collision cross section area $\left(\mathrm{m}^{2}\right)$ of $j^{\text {th }}$ electron impact reaction; $f(\varepsilon)=$ electron energy distribution function (EEDF) and $j \epsilon(1,2,3,4)$.

In many cases, either the Maxwellian EEDF (MEEDF) or the Druyvestein EEDF have been used; for low mean electron energy $(<16.6 \mathrm{eV})$ there is no significant difference between these two distributions [11]. In this work, the Maxwellian EEDF is used since the mean electron energy in the plasma is expected to be low [12]. The Maxwellian EEDF can be expressed as;

$$
\mathrm{f}(\varepsilon)=\gamma^{-1.5} \mathrm{~b}_{1} \mathrm{e}^{\left(-\frac{\varepsilon \mathrm{b}_{2}}{\gamma}\right)}
$$

where $\quad \gamma$-mean electron energy of a single electron

$$
\begin{aligned}
& b_{1}=G(2.5)^{1.5} G(1.5)^{-2.5} \\
& b 2=G(1.25) G(0.75)^{-1}
\end{aligned}
$$

and $G(x)$ is known as Gamma function and given by the following integral;

$$
G(\mathrm{x})=\int_{0}^{\infty} \mathrm{e}^{-\mathrm{v}} \mathrm{v}^{\mathrm{x}-1} \mathrm{dv}
$$

where $v$ is a dummy variable and used to evaluate the integral.

The calculated rate constants of electron impacts are shown in Fig. 1. The cross-section data for the electron impact reactions $\{(1)$ to (4) $\}$ was obtained from [13], [14]. As can be seen there is a significant variation in the way electron impact rate constant varies against the mean electron energy of the plasma. This variation plays a vital role in the NOx and SOx conversion.

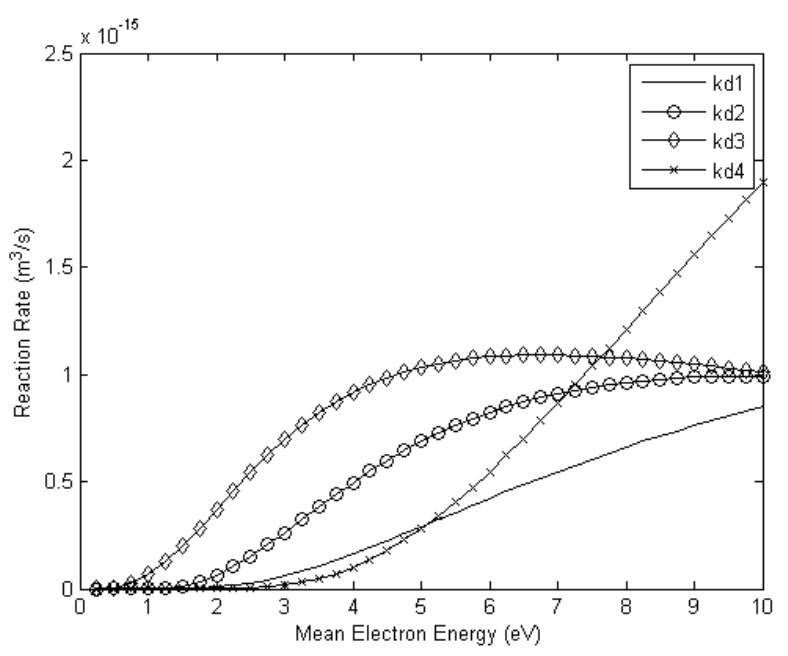

Fig. 1. Electron impact reaction rates for mean electron energies up to 10 $\mathrm{eV}$

\section{RESULTS}

The differential equations of concentration change of each species involved in the reactions (Table I) is derived using mass balanced equations and solved using MATLAB solver ode15s. The key results are shown in Fig. 2. These results were obtained for a typical exhaust composition of a two stroke marine diesel engine; $\mathrm{O}_{2}(13.0 \%), \mathrm{N}_{2}(75.8 \%)$, $\mathrm{CO}_{2}(5.2 \%), \mathrm{H}_{2} \mathrm{O}(5.35 \%)$, NOx (1500 vppm) SOx (600 vppm) and $\mathrm{CO}$ (60 ppm) and $\mathrm{HC}(180 \mathrm{ppm})$.

One of our initial experimental results suggests that MP alone can abate NOx and SOx by $60 \%$ and $80 \%$ respectively from the exhaust of a diesel car engine. The improved MP (so to generate high and more uniform electron density and high dosage of microwave energy) and pre-processed 
exhaust gas (i.e.: temperature controlled and oil particles removed) can increase the abatement proportion greatly.
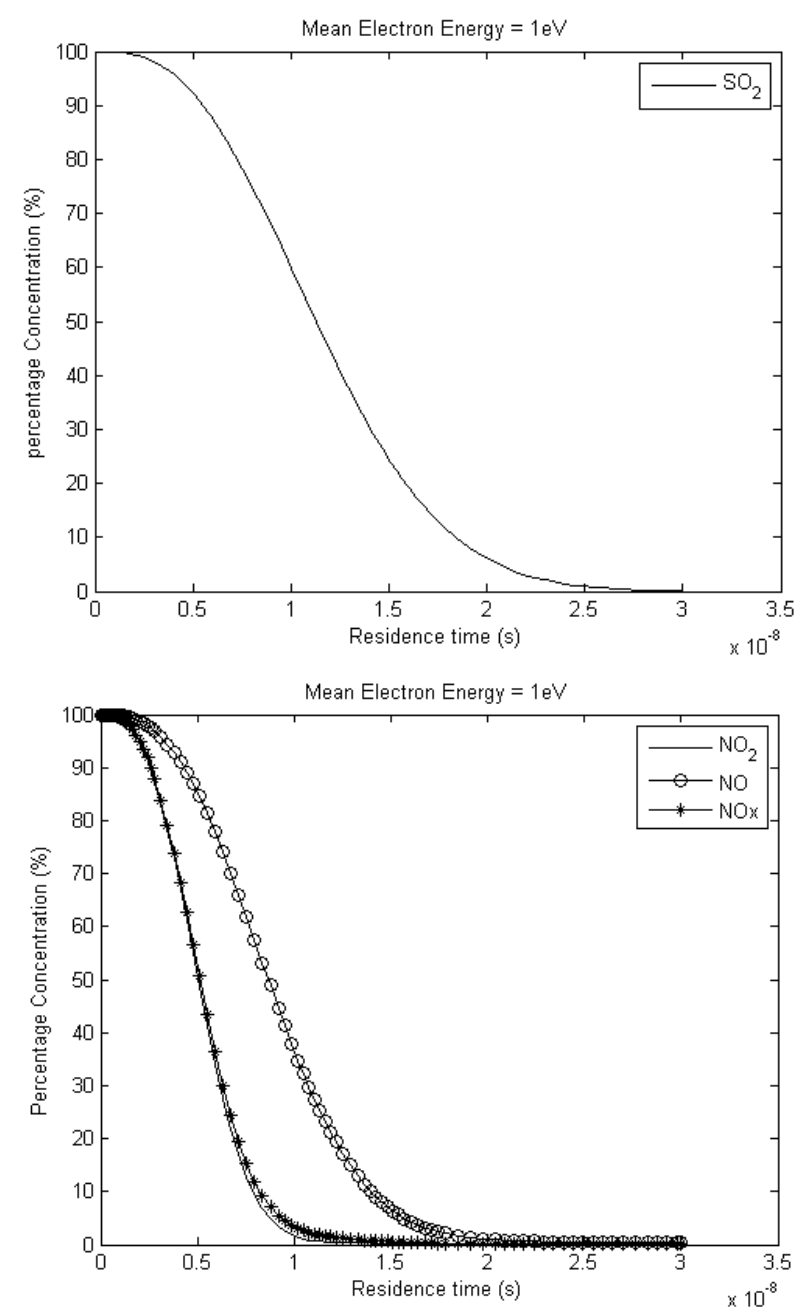

Fig. 2. Abatement of $\mathrm{SO}_{2}$ (top) and NOx (bottom) with NTP : mean electron energy is $1 \mathrm{eV}$

\section{Proposed Electron BeAm + Microwave INTEGRATED NTP}

In addition to MWP, use of electron beam can give a great deal of flexibility in both of the plasma parameters (electron density and mean electron energy) and ability to generate high dosage of plasma energy (i.e.: 9kGy) [8]; making it possible to approach results obtained our numerical prediction. The proposed MP and EB integrated NTPR is shown in Fig. 3. As shown in this figure, single unit NTPR contains a multiple set of magnetrons and a single electron beam for lab scale testing, where flow rate of exhaust gas is very low ( up to $200 \mathrm{l} / \mathrm{s}$ ) and the second figure shows the multiple parallel arrange of a single units to handle large flow rates (up to $800 \mathrm{l} / \mathrm{s}$ ).

The Non-thermal plasma based power plant deNOx and $\mathrm{deSO}_{2}$ uses energy dosage of up to $9 \mathrm{kGy}$ [8]. Based on this dosage, the power required for various exhaust flow rate of marine diesel engine is calculated and plotted in Fig. 4. There will be a significant power difference at high flow rates between low dosage and high dosage; this implies huge energy saving can be achieved when NTP efficient enough to uses low dosage. This will be the focus of our next stage of research.

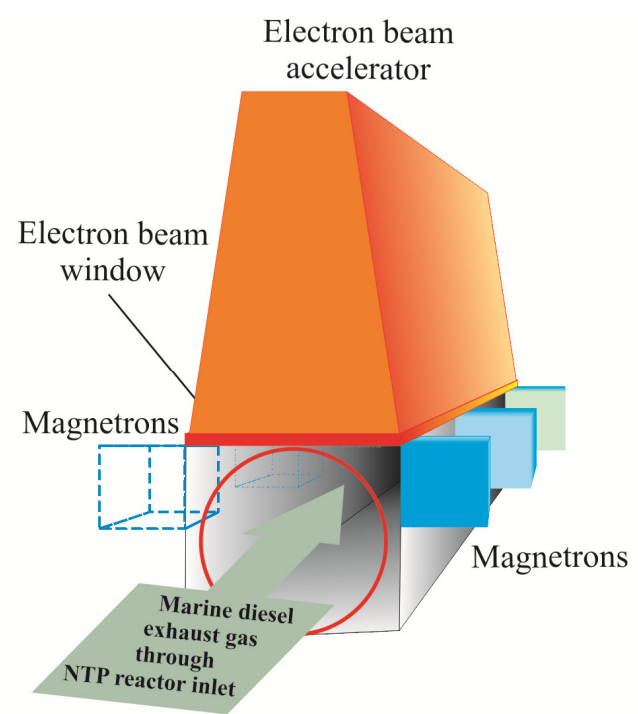

(a) Single unit of NTPR for labs scale testing \{Typical size $-0.5 \mathrm{~m}$ (length) $\times 0.5 \mathrm{~m}($ width $) \times 1.5 \mathrm{~m}($ height $)\}$

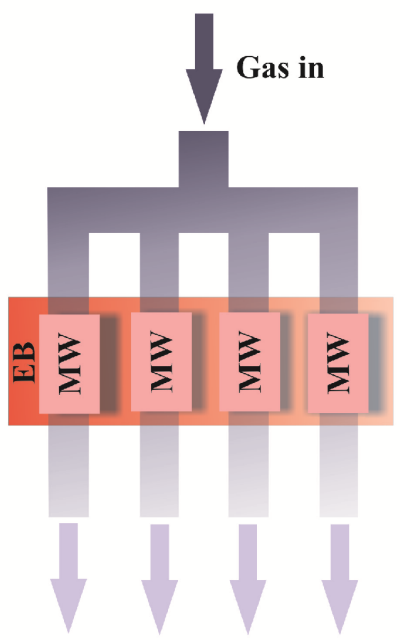

Gas out

(b) Multiple unit NTPR for the pilot scale testing Fig. 3. Proposed integrated (MWI and EB) NTPR

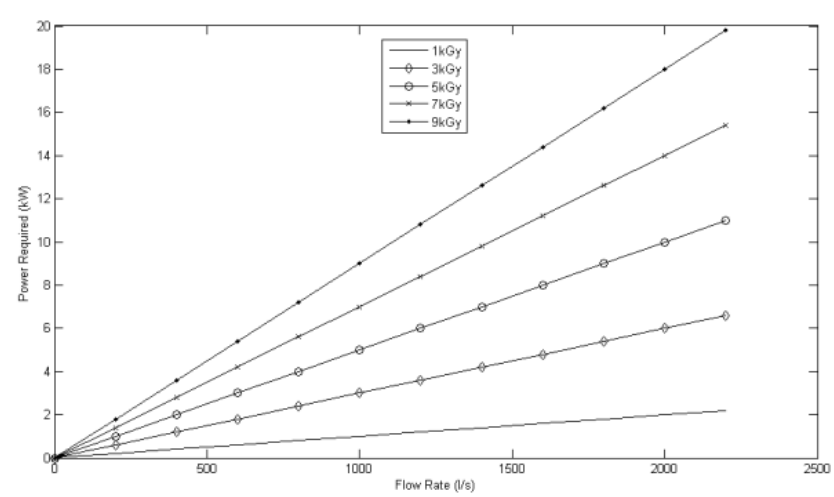

Fig. 4. Power requirement for various exhaust flow rate

\section{CONCLUSIONS}

Abatement of NOx and SOx from exhaust gas of marine engine can be performed with the use of non-thermal plasma. The numerical studies predict that $100 \%$ removal of NOx and SOx is possible. Our initial non-thermal plasma, which was generated by microwave radiation, shows very promising results with $60 \%$ reduction of NOx 
and $80 \%$ SOx. We propose a scheme based on microwaveelectron beam integrated non-thermal plasma to generate required electron energy density and electron energy for both lab-scale testing and pilot scale testing.

\section{REFERENCES}

[1] U.S Environmental Protection Agency. Risk Assessment for Toxic Air Pollutants: A Citizen's Guide. U.S Environmental Protection Agency. (27 December 2012). [Online]. Available: http://www.epa.gov/airtoxics/3_90_024.html.

[2] U.S EPA. Health Effects of Air Pollution. U.S EPA. (13 February 2013). [Online]. Available: http://www.epa.gov/region07/air/quality/health.htm.

[3] International Maritime Organization. Sulphur oxides (SOx) Regulation 14. International Maritime Organization. (2013). [Online].

Available: http://www.imo.org/OurWork/Environment/PollutionPrevention/Air Pollution/Pages/Sulphur-oxides-(SOx)---Regulation-14.aspx.

[4] International Maritime Oganization. Sulphur oxides (SOx) Regulation 13. International Maritime Oganization. (2013). [Online]. Available:

http://www.imo.org/OurWork/Environment/PollutionPrevention/Air Pollution/Pages/Nitrogen-oxides-(NOx)---Regulation-13.aspx.

[5] R. Jurgens, R. Mikaelsen and J. Heslop, "State of the art and efficiency report," EU, Brusells, 2012.

[6] EGCSA, A practical guide to exhaust gas cleaning systems for the maritime industry, London, UK: Sustainable Maritime Solutions Ltd, 2012.

[7] I. Calinescu, D. Ighigeanu, D. Martin, and A. Bulearca, "Electron beam technologies for reducing $\mathrm{SO} 2$ and NOx emissions from thermal power plants," in WEC regional forum - FOREN 2008, Neptun, 2008.

[8] A. Chemielewski, "Application of Ionizing Radiation in Environmental protection," in Radiation treatment of gaseous and liquid effluents for contaminant removal, Bulgaria, 2004.

[9] R. Atkinson, D. Baulch, R. A. Cox, J. N. Crowley, R. F. Hampson Jr., R. G. Hynes, M. M. E. Jenkin, M. J. Rossi, and J. Troe, "Evaluated kinetic and photochemical data for atmospheric chemistry: Volume I - gas phase reactions of Ox, HOx, NOx and SOx species," Atmos. Chem. Phys., vol. 4, pp. 1461-1738, 2004.

[10] R. Atkinson, D. Baulch, R. Cox, R. Hampson Jr., J. Kerr, and J. Troe, "Evaluated Kinetic and Photochemical Data for Atmospheric Chemistry: Supplement III," J. Phys. Chem. Ref. Data, vol. 18, no. 3, pp. 881-1097, 1989.

[11] A. M. Biochenko, G. Evtushenko, S. I. Yakovlenko, and O. Zhdaneev, "Analysis of the Electron Energy Distribution Function in a Copper-Vapour Laser with Modified Kinetics," Laser Physics, vol. 14, no. 7, pp. 922-929, 2004.

[12] R. McAdams, "Prospects for non-thermal atmospheric plasmas for pollution control," J. Phys. D: App. Phy., vol. 34, pp. 2810-2821, 2001.

[13] A. V. Phelps. Electron Scattering Database. University of Colorado. (15 October 2012). [Online]. Available: http://www.lxcat.laplace.univ-tlse.fr/cross sec download.php.

[14] G. Hagelaar and L. Pitchford, "Solving the Boltzmann equation to obtain electron transport coefficients and rate coefficients for fluid models," Plasma Sci Sources and Tech , vol. 14, pp. 722-733, 2005.

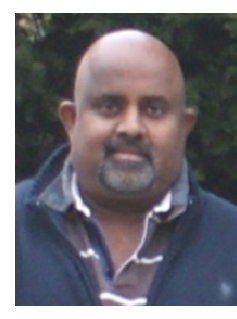

Nada Manivannan is currently working as a research fellow at Centre for Systems Engineering, School of Engineering and Design, Brunel University, London, UK. He previously worked for Motorola, Symbian and Open trade technologies Ltd as an Electronic Engineer for many years. He completed DPhil in Optical Pattern Recognition from University of Oxford, UK in 1997 and BEng (First class Hons) degree in Electrical and Electronic Engineering from City University, UK in
1993. His research interests are Plasma Engineering, Pattern Recognition, Biometrics, Optical Correlators, Mathematical Modelling and Microengineered devices for POCT.

Dr Manivannan is a senior member of IEEE and member of Electrostatics Society of America, USA and member of Oxford university alumni.

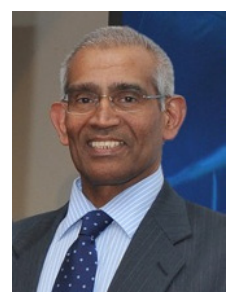

Wamadeva Balachandran is a professor of Electronic Systems and Director of Centre for Electronic Systems Research (CESR) at Brunel University, UK. He served as Head of Department of Systems Engineering at Brunel University from 1999 to 2004. His research interest spans several different disciplines: Electrostatics \& Charge Particle Dynamics, Electrohydrodynamics, Micro/Nano Technologies, Micro-engineered devices for POCT, Biosensors, Optoelectronics, Fingerprint Biometrics, Plasma Engineering and Global Positioning Satellite System for Blind Navigation and Medical Electronics. He has actively pursued research in these interdisciplinary fields for more than 30 years and published over 350 papers to date and filed 15 patent applications. Prof. Balachandran's research has been featured on BBC World Service and TV Broadcasts. He was a Visiting Professor in the Driftmier Engineering Centre at University of Georgia in 1993 and 1996. He is a Visiting Professor at the University of Mansoura, Egypt and Dongguan University, China since 1993 and 1996 respectively. In 2004 he was a Visiting Scholar in the School of Engineering \& Applied Science at University of California, Los Angeles. Prof. Balachandran is a member of the Editorial Board of the Journal of Atomization and Sprays, and the International Journal of Particle Science and Technology. He has served as a paper review manager of IEEE Transactions of Industrial Application Society and a Guest Editor for the Journal of Measurement \& Control. He has a long experience of acting as a consultant in the fields of his research to over 30 companies worldwide.

Prof Balachandran is a Fellow of IEEE, IET, InstPhy, InstMC and RSA.

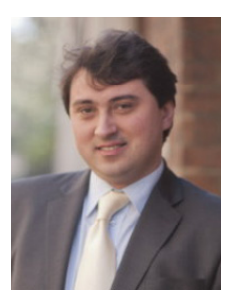

Radu Beleca received the BSc. Eng. degree $\left(1^{\text {st }}\right.$ class, Hons.) from the Faculty of Electrical Engineering, Technical University of Cluj-Napoca, Cluj-Napoca, Romania, in 2007, where he specialized in medical engineering, the MSc. (by research) degree in electrical engineering and fluid mechanics from the University of Poitiers, Poitiers, France, in 2008 and his $\mathrm{PhD}$ at Brunel University, Uxbridge, UK in 2012. His research interests focus on Non-thermal plasma applications, Aerosol Physics, Electrodynamics and fundamental and applied Electrostatics.

Dr Beleca is member of the IEEE Industry Application Society, the Institution of Engineering and Technology, Institute of Physics, UK and Electrostatics Society of America, USA.

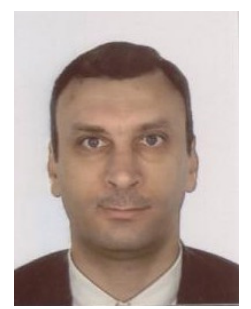

Maysam F. Abbod received the BSc degree in electrical engineering from the Baghdad University of Technology, Baghdad, Iraq, in 1987, and the $\mathrm{PhD}$ degree in control engineering from the University of Sheffield, Sheffield, UK in 1992. He is currently a senior lecture in Intelligent Systems at the School of Engineering and Design, Brunel University, Uxbridge, London UK. His main research interests are in intelligent systems for modelling, control and optimization.

Dr Abbod is a member of IET and a UK Charted Engineer. 